\title{
Taxing Leisure Complements
}

\section{Citation}

Kaplow, Louis. "Taxing leisure complements." Economic Inquiry 48, no. 4 (2010): 1065-1071.

\section{Published Version}

http://dx.doi.org/10.1111/j.1465-7295.2009.00230.x;http://onlinelibrary.wiley.com/doi/10.1111/ j.1465-7295.2009.00230.x/full

\section{Permanent link}

http://nrs.harvard.edu/urn-3:HUL.InstRepos:11222733

\section{Terms of Use}

This article was downloaded from Harvard University's DASH repository, and is made available under the terms and conditions applicable to Open Access Policy Articles, as set forth at http:// nrs.harvard.edu/urn-3:HUL.InstRepos:dash.current.terms-of-use\#OAP

\section{Share Your Story}

The Harvard community has made this article openly available.

Please share how this access benefits you. Submit a story.

\section{Accessibility}




\title{
HARVARD
}

JOHN M. OLIN CENTER FOR LAW, ECONOMICS, AND BUSINESS

\section{TAXING LEISURE COMPLEMENTS}

\author{
Louis Kaplow
}

Discussion Paper No. 621

$10 / 2008$

Harvard Law School

Cambridge, MA 02138

This paper can be downloaded without charge from:

The Harvard John M. Olin Discussion Paper Series: http://www.law.harvard.edu/programs/olin_center/

The Social Science Research Network Electronic Paper Collection: http://papers.ssrn.com/abstract_id=\#\#\#\#\#\# 


\title{
Taxing Leisure Complements
}

\author{
Louis Kaplow*
}

\begin{abstract}
Ever since Corlett and Hague (1953), it has been understood that it tends to be optimal on second-best grounds to (relatively) tax complements to leisure and subsidize substitutes because doing so helps to offset the distorting effect of taxation on labor supply. Yet in the context of simultaneous optimization of a nonlinear income tax and commodity taxes, Atkinson and Stiglitz (1976) claim to have demonstrated the opposite, that goods complementary with leisure should "face lower tax rates, whereas substitutes face higher tax rates." Derivations in leading texts on optimal taxation seem to yield opposing conclusions regarding the sign of optimal deviation of commodity taxes from uniformity. It is demonstrated that the optimality of relatively taxing leisure complements is indeed correct, and conflicting results are explained.
\end{abstract}

JEL Classes: H21, H24

Keywords: income taxation, commodity taxation, optimal taxation, leisure complements

(C) Louis Kaplow. All rights reserved.

*Harvard University and National Bureau of Economic Research. I am grateful to Tim Brennan (the editor), the referees, Robin Boadway, Peter Diamond, James Hines, and Dan Silverman for helpful comments and discussions, and to the John M. Olin Center for Law, Economics, and Business at Harvard University for financial support. 


\section{Introduction}

Income taxation distorts labor effort downward. Accordingly, it tends to be optimal on second-best grounds to set other policy instruments so as to introduce additional distortions if (though only if) doing so helps to mitigate the excessive consumption of leisure.

This principle has been considered most extensively with regard to differential commodity taxation. In a Ramsey setting, Corlett and Hague (1953) showed that it is optimal to tax complements to leisure and to subsidize substitutes - relatively speaking - which serves to offset the distorting effect of taxation on labor supply.

Consider a simple example for concreteness. Begin with a labor income tax, which as is well known induces individuals to reduce labor effort, increasing leisure. (This is the substitution effect; even if the income effect is so large that uncompensated labor supply does not fall, it is the substitution effect that matters for efficiency.) Ideally, we would like to tax leisure directly or otherwise adjust the income tax to avoid this inefficiency, but this is assumed to be impossible because the government can only observe income and not the amount of labor effort that contributed to producing it. This preexisting inefficiency raises the possibility that other, more indirect instruments may have a role to play, and indeed they do, specifically with regard to commodity taxation.

To develop this possibility further, suppose that disposable income is spent on two goods, pizza and swimsuits. Think of pizza as a benchmark good that produces utility equally well in all settings, whether at work or at play, including at the beach or swimming pool. Swimsuits are classic leisure complements: having more swimsuits enhances utility to a greater extent the more time one has to swim, whereas swimsuits produce no additional value while at work. In this setting, the Corlett-Hague argument suggests the optimality of a relative tax on swimsuits. To be sure, this will impose an efficiency cost by distorting individuals' consumption (too few swimsuits, too much pizza), but that cost is second-order as the tax is imposed starting at a level of zero. The other effect of the tax will be to make leisure less attractive, now that individuals consume fewer swimsuits. This, in turn, will raise labor effort. Since labor is distorted downward by the income tax, this effect entails a first-order efficiency gain. Therefore, it is indeed the case that imposing some positive relative tax on swimsuits, the leisure complement, is optimal.

Analysis of these matters became more formal with Atkinson and Stiglitz's (1976) seminal examination of the simultaneous optimization of a nonlinear income tax and commodity taxes. The article is most famous for its uniformity result: if labor is weakly separable in the utility function, the optimum is characterized by no differential commodity taxation. ${ }^{1}$ Although many Ramsey principles (for example, the inverse elasticity rule) do not survive the introduction of an income tax, the Corlett-Hague result that it tends to be optimal to tax leisure complements

\footnotetext{
${ }^{1}$ Kaplow (2006) and Laroque (2005) generalize this result to the case in which the income tax need not be optimal and in other respects, and Kaplow (2008) discusses a variety of other qualifications to the uniformity result and how the analysis relates to that in familiar models of Ramsey taxation.
} 
and subsidize substitutes is widely understood to remain intact. ${ }^{2}$

Surprisingly, this generally accepted understanding seems to be contradicted by Atkinson and Stiglitz (1976). Their central analytical contribution in the relevant part of the article is their derivation of an expression for optimal taxation of any given commodity (relative to the tax rate on commodity 1, arbitrarily set equal to zero as a benchmark). First, they use their derivation to establish their uniformity result in the case of weak separability. When the utility function has the stated feature, one of the terms in their expression for the optimal commodity tax rate on good $i$ equals zero (and this is true for all $i$ ), so no commodity taxation is optimal. However, regarding the more general case, Atkinson and Stiglitz (1976) state: "From the results given above, it follows that goods which are complementary . . with leisure . . will face lower tax rates, whereas substitutes face higher tax rates" (p. 68, emphasis added). ${ }^{3}$ Myles's (1995) text presents a similar derivation that produces an analogous formula, after which it states: "Therefore, those goods relatively preferred by the consumers supplying most labour should be taxed more" (p. 164, emphasis added) - that is, the government should tax labor complements, equivalent to leisure substitutes, rather than leisure complements.

Not all statements in the literature are in accord. For example, Salanié's (2003) text begins with essentially the same set-up as the others use, derives a formula that (when adjusted to conform with those in other sources) has the opposite sign, and states "In more economic terms, government should tax more heavily goods that are more complementary to leisure" ( $p$. 116). Although he states that his uniformity result (for the case of weak separability) is due to Atkinson and Stiglitz), he fails to mention the difference in sign or in conclusion for the more general case. The more familiar prescription also appears in Myles (1995), who, after the opposing language quoted above, goes on to state: "goods for which demand increases if more leisure is obtained, but with no change in income, should have positive commodity taxes introduced" (p. 165).

What's the right answer? And how can we explain the contradictory results? The Corlett-Hague suggestion - that it is optimal (relatively) to tax leisure complements and to subsidize substitutes - is indeed correct, and for just the reason presented above. The explanation for (most of) the contradictory results is simple, yet subtle. Authors' derivations vary in how they present the Hamiltonian (the analogy in optimal control theory to the Lagrangian). In a common formulation - used, for example, in Atkinson and Stiglitz (1976) - the relevant multiplier (the costate variable) turns out to be negative. This multiplier, moreover, appears in the various formulas for the optimal commodity tax rate on each commodity. It seems, however, that authors (and one supposes readers) in this literature have interpreted the resulting expressions on the implicit assumption that the multiplier is positive. This "missing" minus sign reverses all interpretations (including those that confirm the standard

\footnotetext{
${ }^{2}$ This view is reflected, for example, in empirical work that considers the optimality of taxing forms of consumption that may be significant leisure complements. See Iorwerth and Whalley (2002), West and Williams (2007), and Parry and West (2007).

${ }^{3}$ Omitted by the ellipses is the point that "complementary" is used "in the Edgeworth, not the more usual Hicksian, sense," which means in Atkinson and Stiglitz's notation that $U_{i L}<0$. The precise concept is elaborated below, in the interpretation of expression (6).
} 
view), except of course when another term equals zero, which arises in the case of weak separability that produces the uniform commodity tax result. ${ }^{4}$

The remainder of this note briefly presents the typical formulation of the problem and the standard result, explains why the pertinent costate variable in that set-up is negative, and thus reconciles existing derivations with the intuition deriving from Corlett and Hague.

\section{Analysis}

\subsection{Model}

Individuals' utilities $u\left(x_{1}, \ldots, x_{n}, l\right)$ depend on their level of consumption of $n$ commodities, $x_{1}, \ldots, x_{n}$, and on their level of labor effort, $l$. Individuals vary in their wage rates, $w$, which have density function $f(w)$. Individuals' before-income-tax income is $w l$. There is a nonlinear income tax $T(w l)$ - which, following convention, may be negative, as tends to be optimal for low-income individuals - and commodity taxes on each good $x_{i}$ are $\tau_{i}$ (which may be subsidies, in which case they are negative). ${ }^{5}$ Producer prices for each commodity are assumed to be constant and may be normalized to 1. Accordingly, an individual's budget constraint is

(1) $\sum_{i=1}^{n} x_{i}\left(1+\tau_{i}\right)=w l-T(w l)$.

The government's problem is to maximize social welfare,

(2) $\int_{0}^{\infty} W(u(w)) f(w) d w$

where $W$ is a concave welfare function and $u(w)$ denotes the level of utility achieved by an individual with wage level (of type) $w$. In maximizing expression (2), the government faces two constraints. The resource constraint (which sometimes is equivalently formulated as a constraint on government revenue ${ }^{6}$ ) is

(3) $\int_{0}^{\infty}\left(w l(w)-\sum_{i=1}^{n} x_{i}(w)\right) f(w) d w=R$,

\footnotetext{
${ }^{4}$ For statements in accord with conventional wisdom that are reversed once the multiplier is correctly interpreted, the explanation is either a discrepancy between a verbal statement and the corresponding derivation or, in one instance, an apparent sign error (see note 11).

${ }^{5}$ Atkinson and Stiglitz (1976) allow commodity taxes to be nonlinear, but this complication is ignored here because it is not central for present purposes, is omitted in others' analyses, and is often thought to be infeasible (due to arbitrage).

${ }^{6}$ The term in large parentheses in expression (3) is individuals' production minus their consumption. This difference also equals the sum of taxes (net of subsidies) that individuals pay, so the left side of expression (3) also measures total tax revenue.
} 
where $l(w)$ and $x_{i}(w)$ refer to levels of labor effort and consumption chosen by individuals of type $w$, and $R$ is the level of resources required by the government.

In addition, there are incentive constraints. These arise because the government, although able to observe an individual's income, $w l$, and commodity purchases, is assumed to be unable to observe individuals' $w$ 's (or l's). Under standard assumptions, the binding constraints of concern are that individuals might wish to imitate types just below their own, specifically by reducing labor effort slightly so as to earn the same income as the lower type. (That is, since the mimickers' $w$ is higher than the type whom they are imitating by earning the same income - which is all the tax authority can observe - they are accomplishing this by reducing their labor effort $l$, which, ceteris paribus, raises their utility). To prevent such mimicking behavior and thus for the government's scheme to be incentive compatible, it is necessary that utility rise with $w$ at a sufficient rate, which condition is usually expressed as

$$
\text { (4) } \frac{d u(w)}{d w}=\frac{-u_{l} l}{w} \equiv g(w) \text {. }
$$

See, for example, Mirrlees (1971). This expression for the rate at which $u(w)$ must increase with $w$ (redefined as $g(w)$ for convenience) can be obtained by taking the derivative of $u$ with respect to $w$, making the assumption that all of an individual's response is channeled through a downward adjustment in $l$ (which yields a valid result because, at the individual's optimum, all margins of response have the same effect on utility). Since disposable income is therefore constant, so is earned income, $w l$; hence, the change in $l$ is given by $-l / w$. To obtain the effect of this change in $l$ on the individual's utility, the change is weighted by $u_{l}$, the derivative of the individual's utility function with respect to labor effort.

Thus, the government chooses $T(w l)$ and the $\tau_{i}$ to maximize expression (2) for social welfare subject to the revenue constraint (3) and incentive constraints (4). It has become standard to use optimal control theory in solving this problem. There are various choices for the control variables: the formulation here will follow Atkinson and Stiglitz (1976) in having the control variables be labor effort $l$ and commodities $x_{2}, \ldots, x_{n}$ (commodity $x_{1}$ is omitted because, from the budget constraint (1), it is automatically determined when the other variables are chosen). Individuals' utility levels $u(w)$ are taken as the state variable, so that expression (4) indicates the rate of change in the state variable (here, over type, rather than over time, as in many familiar control problems in economics).

The Hamiltonian is ordinarily expressed as follows:

(5)

$$
H\left(u, x_{2}, \ldots, x_{n}, l, \lambda, \mu, w\right)=\left[W(u(w))+\lambda\left(w l(w)-\sum_{i=1}^{n} x_{i}(w)-R\right)\right] f(w)+\mu(w) g(w)
$$

where $\lambda$ is a conventional Lagrange multiplier (here indicating the shadow value of a dollar in resources or, equivalently, government revenue) and $\mu(w)$ is the costate variable, a shadow price concerning the incentive constraint in expression (4). (More will be said about the interpretation 
of the costate variable in a moment.)

Before proceeding, it will be helpful for readers who may wish to compare expression (5) with corresponding expressions in other work to note some points that relate to the sign on the costate variable. First, some authors use a minus sign rather than a plus sign for the final term. As is familiar from Lagrange multipliers, there is nothing wrong with this, but the sign of the resulting costate variable will be reversed. Below, when I refer to the costate variable being negative, I have the presentation in expression (5) specifically in mind. Second, some authors use expression (4) to substitute for $g(w)$ when formulating the Hamiltonian. This too is equivalent, but notice that the substituted value from expression (4), $-u_{l} l / w$, has a leading minus sign; hence, when a Hamiltonian of this alternative form has a minus sign before the last term, it is equivalent to expression (5) (and, when a plus sign is used in the alternative case, it is equivalent to using a minus sign here). ${ }^{7}$

This Hamiltonian (5) is maximized with respect to all of the $x_{i}$ (excepting $x_{1}$, as noted) and substitutions are made using individuals' first-order conditions for their choice of commodities. Furthermore, it is common to set $\tau_{1}$ equal to zero as a normalization. This is important in understanding the result because all assessments of complementarity are relative to good $x_{1}$, and accordingly a positive (negative) value for any particular $\tau_{i}$ indicates that the good $x_{i}$ should be taxed (subsidized) relative to good $x_{1}$. With this normalization in mind, the maximization yields the following condition, which holds for $i=2, \ldots n$ (and also, trivially, for $i=1):^{8}$

${ }^{7}$ There is yet another complication: some analysts state utility to be a function of leisure rather than of labor, which is often the source of an additional negative sign (or one less): in the analogue to expression (4), there is no minus sign, but $u_{l}$ is replaced by the derivative of utility with respect to leisure, which has the opposite sign.

${ }^{8}$ Expressed in the present notation, the derivative is

$$
\frac{\partial H}{\partial x_{i}}=-\lambda\left[\left(\frac{\partial x_{1}}{\partial x_{i}}\right)+1\right] f(w)-\frac{\mu(w) l}{w}\left[u_{l 1}\left(\frac{\partial x_{1}}{\partial x_{i}}\right)+u_{l i}\right]=0 .
$$

The partial derivative that appears twice in parentheses can be understood as the mechanical change in $x_{1}$ as $x_{i}$ changes, as dictated by the budget constraint (1) (recalling that $x_{1}$ is not a control variable, but instead is thus determined as the control variables $l$ and the other $x_{i}$ are adjusted). Using this fact to substitute for the partial derivative where it first occurs (the derivative equals $\left.-\left(1+\tau_{i}\right) /\left(1+\tau_{1}\right)\right)$; further taking advantage of individuals' first-order conditions to note that this ratio in turn equals $-u_{i} / u_{1}$, which may be used in the second instance; using the fact that $\tau_{1}$ is normalized to zero; and moving the second term to the right side yields

$\lambda f \tau_{i}=\frac{\mu l}{w}\left[-\frac{u_{l 1} u_{i}}{u_{1}}+u_{l i}\right]$

Again, using individuals' first-order condition and the normalization, we can multiply the left side by $1 /\left(1+\tau_{i}\right)$ and (equivalently) multiply the right side by $u_{1} / u_{i}$; then, dividing both sides by $\lambda f$ and making use of the definition of log, we can produce expression (6). 
(6) $\frac{\tau_{i}}{1+\tau_{i}}=\frac{\mu l u_{1}}{\lambda w f} \frac{d \log \left(\frac{u_{i}}{u_{1}}\right)}{d l}$.

With weak separability between labor and all commodities (as a group) - that is, when the utility function can be stated as $\mathrm{u}\left(v\left(x_{1}, \ldots, x_{n}\right), l\right)$, where $v$ is a subutility function-the derivative on the right size of expression (6) is zero for all $i$. Hence, in this case, optimal commodity taxes are all equal to zero (which was the benchmark rate stipulated for $x_{1}$ ).

Suppose now that some good $i$ (relative to good 1 ) is complementary to leisure. This means that, as $l$ increases and accordingly the individual enjoys less leisure, good $i$ becomes relatively less valuable. In this case, the derivative on the right side of expression (6) is negative. If all the other terms were positive, this implies that the optimal $\tau_{i}$ is negative, corresponding to a subsidy on the leisure complement.

Before returning to the other terms, let us briefly revisit the example from the introduction with two goods, pizza $\left(x_{p}\right)$ and swimsuits $\left(x_{s}\right)$. To capture the idea that pizza is valuable without regard to labor effort whereas swimsuits' value depends on the extent of leisure time available, suppose that utility is given by $u\left(x_{p}, x_{s}, l\right)=v_{p}\left(x_{p}\right)+(1-l) v_{s}\left(x_{s}\right)-z(l)$, where each subutility function has the usual properties. It is straightforward to show that, in this case, the derivative on the right side of expression (6) equals $-1 /(1-l)$, which is negative.

Now consider elements of the first term on the right side of (6), skipping for the moment the costate variable $\mu$ : $l$ is positive (we are considering only interior solutions, as is standard in the literature); $u_{1}$ is the marginal utility of the first commodity, which is positive; $\lambda$ is the multiplier on resources (or, equivalently, on the government's budget), which is positive; $w$ is the individual's wage rate, taken to be positive; and $f$ is the density of the distribution (evaluated at $w$ ), also taken to be positive. Hence, the sign of the derivative indeed indicates the sign of the optimal commodity tax, suggesting that we should subsidize leisure complements (swimsuits in the example) if and only if the sign of the costate variable, $\mu$, is positive. If, instead, the sign of $\mu$ is negative, the Corlett-Hague intuition is correct. Accordingly, the next step is to explain why the sign of $\mu$ is indeed negative (contrary to the apparently standard implicit assumption when interpreting conditions like expression (6), as illustrated by the quotations in the introduction). ${ }^{9}$

\footnotetext{
${ }^{9}$ There is a further, generally overlooked complication in interpreting expression (6). Most terms on the right side - in general, all of them except the multiplier $\lambda$ - are themselves functions of $w$. (This includes the costate variable, $\mu(w)$, as will be apparent in section 2.2.) Accordingly, the optimal level of each commodity tax is determined, in principle, for each type $w$. However, it is ordinarily supposed that commodity taxes are anonymous (and must be so, for the most part, due to the possibility of arbitrage). This problem is inconsequential for Atkinson and Stiglitz's (1976) result concerning uniformity in the case of weak separability. Because each type's optimal commodity tax vector is zero, the inability to differentiate by type does not disrupt the posited optimum. For the general case, however, which is pertinent to analyses implying the optimality of taxing leisure complements and subsidizing substitutes, this problem is material. If some good (say, swimsuits, in the above example) is a leisure complement for everyone, then it is optimal for everyone to face a positive relative tax on that good. Even so, the optimal level of that tax would in general depend on an individual's type $w$. Accordingly, the optimal anonymous commodity tax on that good will reflect some sort of weighted
} 


\subsection{The Sign of the Costate Variable}

Understanding the intuition behind the costate variable can be a bit tricky, a fact confirmed by many discussions I have had in preparing this article (in which most queried were unsure, many stated it was indeed tricky, and some offered conjectures that were incorrect). For simpler optimal control problems, like choosing a path of consumption over time given an expression for how the capital stock evolves (and a starting and ending value for the capital stock), the costate variable at time $t$ indicates how much the objective function is increased by a unit increment to the state variable (the capital stock) at time $t$. (The economic interpretation is presented in Dorfman (1969); a helpful exposition appears in the text by Léonard and Long $(1992, \S 4.5)$, which is in turn based on the formal derivation in Léonard (1987); see also Kamien and Schwartz (1981, §II.4).) In these familiar problems, the costate variable is positive: additional capital at time $t$ is valuable because one can consume more at some point in the future while still satisfying the pertinent constraints.

The challenge is in carrying this intuition over to the optimal income tax problem. Here, the state variable is utility $(u)$; instead of tracing an evolution over time, we have an evolution across types $(w)$. Moreover, the relationship governing that evolution derives not from technology (for example, how capital is converted into output or how capital depreciates) but instead from incentive constraints. Specifically, the equation of motion, speaking metaphorically, is expression (4).

To understand what is involved in the present setting, consider what happens if, at some wage level $w, g(w)$ is increased by a small increment, it being as if a small unit of utility is deposited like manna from heaven. At first, this would seem to be a good thing. But it isn't. The direct effect is second order, for the benefited group includes solely those who are precisely of type $w$, which is a group of measure zero (this problem has a continuum of types, which is typical in optimal control problems of this form). The indirect effect relates to the equation of motion, expression (4). This equation presents the incentive constraints, which are tightened for higher types by the hypothesized increment to $g(w)$ at the chosen $w$, which results in a loss in achievable social welfare. The heuristic argument is as follows.

When utility at the precise point $w$ is raised slightly in the manner indicated, individuals of slightly higher types will now want to mimic those of type $w$. After all, at the postulated optimum, where the constraints embodied in expression (4) were binding, such individuals were indifferent. But now, by stipulation, mimicking yields slightly higher utility, so indifference is broken. Accordingly, to restore the constraint, the controller is required to raise utility of this potential mimicker. To do this, the type's taxes must be reduced. But now, what about the next higher type? That individual, who was previously indifferent, now faces a better outcome from mimicking the type whose taxes were just reduced and thus must also have taxes reduced to

average of these optimal type-specific rates. (The same reasoning applies if some good is a leisure complement for some types of individuals but a substitute for others, which in general is possible.) More precisely, the proper formulation of the optimal control problem needs to reflect that the commodity tax rates are constrained to be uniform across types: they may vary across goods, but that exhausts the available flexibility. 
restore incentive compatibility. And so on up the line.

When the process is completed, all individuals whose type is above $w$ will have higher utility, a good thing. However, they all have higher utility because they pay lower taxes than before, a bad thing, the weight of which is given by $\lambda$, the shadow price on the resource (revenue) constraint. Which effect on social welfare is greater? It is apparent that the latter, negative effect dominates. After all, what has just been wrought is a redistribution from the treasury to the upper portion of the population. One way to make the revenue cost concrete is to suppose that it is paid for by cutting the uniform grant to the population - that is, the intercept of the nonlinear income tax schedule, $T(0)$, which is typically negative. (Since $\lambda$ is the shadow price of resources or revenue, at the optimum it represents the value of any marginal use of the revenue through adjustments to the available instruments, including the one just described.)

In addition to this heuristic explanation, the result can be derived formally. Indeed, this has been done (implicitly or explicitly) in derivations of the optimal nonlinear income tax in the case in which there is only one type of consumption and thus no place for differential commodity taxation. The maximum principle used in optimal control theory includes the condition that the rate of change of the costate variable equals the negative of the partial derivative of the Hamiltonian with respect to the state variable. In the present formulation, this means that $d \mu(w) / d w=-\partial H / \partial u(w)$. Analysts then integrate this function to infinity, making use of the Fundamental Theorem of Calculus and the transversality condition (indicating that $\mu(w)=0$ at the upper limit of the distribution of $w$, or as $w$ approaches infinity, as the case may be), to yield an expression for $\mu(w)$, which is typically derived for the special case of quasi-linear preferences. ${ }^{10}$ See, for example, Salanié (2003, pp. 93-94). Those expressions indeed match the above intuitive explanation.

Accordingly, the sign of the costate variable $\mu(w)$ is negative (except at the endpoints of the distribution, as just suggested, a detail that will be ignored here). It follows, therefore, that we must include in our minds a minus sign preceding the derivative term on the right side of expression (6) for the optimal commodity tax. Furthermore, as noted above, if the Hamiltonian (5) were instead formed with a minus sign preceding the costate variable, the costate variable would then be positive (as usually imagined), but in that case the additional minus sign would carry through and appear explicitly in an analogue to expression (6). ${ }^{11}$

\footnotetext{
${ }^{10}$ More precisely, the integral is from the upper limit to the stated $w$, so a minus sign is introduced. Quasi-linear preferences refer (in this one-good case) to utility equal to consumption minus a function indicating the disutility of labor.

${ }^{11}$ The result in Salanié (2003) that was mentioned in the introduction still has not been fully explained. It is stated there that he starts with the same formulation as the others: one can verify this by comparing his Hamiltonian (p. 115) with those in Atkinson and Stiglitz (1976, p. 67) and Myles (1995, p. 164) — note that they all follow the present approach of using a plus sign before the costate variable although this is less apparent since they use the aforementioned substitution using expression (4), so a minus sign appears (recall that this minus sign is from the right side of the equals sign in expression (4) and not part of the formulation of the Hamiltonian). Furthermore, Salanié's final result (p. 116) seems to be of different sign from the results in the other two writings (this can only be determined after some manipulation, since the left side of Salanié's analogue to expression (6) is presented differently). It appears that the explanation is a sign error in Salanié's derivation on p. 115 in moving from his Hamiltonian to his expression (1). Accordingly, although the introduction identified Salanié (2003) as the one text that is formally in support of the familiar intuition, once the apparent sign error is corrected his text seems to become yet another voice against the intuition based
} 


\section{Conclusion}

This article demonstrates that the common intuition on the second-best optimality of taxing leisure complements is correct despite contrary results in the formal literature on the optimal taxation of commodities in the presence of an income tax. The formal derivation and accompanying discussion of intuition help to resolve the conflict in the literature. This result is not only important conceptually but has growing policy significance as researchers increasingly identify important categories of consumption (such as food, gasoline, and alcohol; see the literature cited in note 1) that may be significantly complementary with leisure.

on Corlett and Hague. 


\section{References}

Atkinson, A.B., Stiglitz, J.E., 1976. The design of tax structure: direct versus indirect taxation. Journal of Public Economics 6, 55-75.

Corlett, W.J., Hague, D.C., 1953. Complementarity and the excess burden of taxation. Review of Economic Studies 21, 21-30.

Dorfman, R., 1969. An economic interpretation of optimal control theory. American Economic Review 59, 817-831.

Iorwerth, A.A., Whalley, J., 2002. Efficiency considerations and the exemption of food from sales and value added taxes. Canadian Journal of Economics 35, 166-182.

Kamien, M.I., Schwartz, N.L., 1981. Dynamic Optimization: The Calculus of Variations and Optimal Control in Economics and Management. New York: North Holland.

Kaplow, L., 2008. The Theory of Taxation and Public Economics. Princeton: Princeton University Press.

Kaplow, L., 2006. On the undesirability of commodity taxation even when income taxation is not optimal. Journal of Public Economics 90, 1235-1250.

Laroque, G., 2005. Indirect taxation is superfluous under separability and taste homogeneity: a simple proof. Economics Letters 87, 141-144.

Léonard, D., 1987. Co-state variables correctly value stocks at each instant: a proof. Journal of Economic Dynamics and Control 11, 117-122.

Léonard, D., Long, N.V., 1992. Optimal Control Theory and Static Optimization in Economics. New York: Cambridge University Press.

Mirrlees, J.A., 1971. An exploration in the theory of optimum income taxation. Review of Economic Studies 38, 175-208.

Myles, G.D., 1995. Public Economics. Cambridge: Cambridge University Press.

Parry, I., and West, S.E., 2007. Alcohol/leisure complementarity: empirical estimates and implications for tax policy. Unpublished manuscript.

Salanié, B., 2003. The Economics of Taxation. Cambridge, Mass.: MIT Press.

West, S.E., Williams, R.C. III, 2007. Optimal taxation and cross-price effects on labor supply: estimates of the optimal gas tax. Journal of Public Economics 91, 593-617. 